\title{
Burnout and Empathy: A Cross-Sectional Study among Resident Physicians in Public Sector Hospitals of a Developing Country
}

\author{
Muhammad Hamza Khalid, Rafia Ishtiaq, Laiba Fatima, Hassaan Ahmed, Aqsa Masood, \\ Tayyab Mumtaz Khan, Hajira Sajid, Rida Qaiser, Mahnoor Awan, and Daneyal Arshad
}

\section{ABSTRACT}

\begin{abstract}
The main objective of our study was to determine the prevalence of burnout and to identify various socio-demographic factors which are associated with resident burnout. As a secondary objective, we aimed to assess levels of empathy among the residents. A descriptive cross-sectional study was performed among residents working in Holy Family Hospital, Benazir Bhutto Hospital, and District Headquarter Hospital, all of which are situated in district Rawalpindi of Punjab, Pakistan. Data were collected from January 2019 to April 2019 using a convenient sampling technique. The participants were requested to complete Maslach Burnout Inventory to measure burnout and Jefferson Scale of Physician Empathy to measure empathy from January 2019 to April 2019. For data analysis IBM SPSS (C) version 25.0 was used. Descriptive statistics were used to summarize the quantitative variables. Chi-square test was used to determine the association between burnout and categorical variables. Then, those independent variables with $\mathrm{p}$-value $<0.05$ were subjected to binary logistic regression to identify predictors of burnout. A P-value of $<0.05$ was used as the criterion for statistical significance and OR with $95 \%$ confidence interval was used to indicate the strength of association. Independent sample t-test was used to assess empathy among the groups. The prevalence of burnout in our sample was $78 \%$. The average burnout score of the sample was $81 \pm 13.45$. Weekly working hours $(p$-value $<0.05)$ and the type of specialty (p-value < 0.05 ) were significantly associated with resident burnout. Residents working more than 80 hours were more prone to develop burnout [AOR 2.700(1.42-5.120)]. Medical residents were found to be at a higher risk of developing burnout as compared to surgical residents [(AOR 2.097(1.16-3.78)]. Residents working less than 80 hours per week had more empathy scores as compared to residents working more than 80 hours and this result was statistically significant (p-value $<\mathbf{0 . 0 5}$ ). However, no significant difference in empathy was found for the age, gender, marital status, and posts. Therefore, weekly working hours should be reduced to diminish burnout and increase empathy, thereby, promoting the quality of care being delivered to the patient. Moreover, efforts should be made to reduce burnout in medicine residents so that we may promote the doctorpatient relationship.
\end{abstract}

Keywords: Burnout, Country, Developing, Empathy, Hospitals, Public, Resident.
Submitted : June 24, 2021

Published : August 10, 2021

ISSN: $2593-8339$

DOI: $10.24018 /$ ejmed.2021.3.4.945

Muhammad Hamza Khalid*

Rawalpindi Medical University, Rawalpindi, Pakistan.

(e-mail: hamza20092878@ gmail.com) Rafia Ishtiaq

Rawalpindi Medical University, Rawalpindi, Pakistan.

Laiba Fatima

Rawalpindi Medical University, Rawalpindi, Pakistan.

Hassaan Ahmed

Rawalpindi Medical University, Rawalpindi, Pakistan.

Aqsa Masood

Rawalpindi Medical University,

Rawalpindi, Pakistan.

Tayyab Mumtaz Khan*

Rawalpindi Medical University, Rawalpindi, Pakistan.

(e-mail: tayyab.mkhan98@gmail.com) Hajira Sajid

Rawalpindi Medical University,

Rawalpindi, Pakistan.

Rida Qaiser

Rawalpindi Medical University,

Rawalpindi, Pakistan.

Mahnoor Awan

Rawalpindi Medical University,

Rawalpindi, Pakistan.

Daneyal Arshad

Rawalpindi Medical University,

Rawalpindi, Pakistan.

*Corresponding Authors

\section{INTRODUCTION}

Doctor-patient relationship has undergone striking changes in the recent past [1]. Expectations associated with an attending physician have tremendously increased due to an ever-growing access to information, patient centered care and social changes [2]. In response to these changes, the medical community has realized the importance of not only increasing awareness of the impact of doctors' attitudes on clinical outcomes and patient satisfaction, but also bolstering up a culture of inculcating communication skills, resilience and empathy [1], [2]. Clinical empathy is a cognitive (as opposed to affective) attribute that involves an understanding of the inner experiences and perspectives of the patient, combined with a capability to communicate this understanding to the patient [3]. Empathy can be regarded as a royal tool to establish an optimal physician-patient rapport and is an essential component of quality care being delivered to the patient [2]. It cultivates a deeper interpersonal relationship, thus, enhancing compliance to medical treatment and improvement in clinical outcomes [4], [5]. It has also been linked with positive attitudes towards elderly, competence in history taking and performing physical examinations and patient satisfaction [3]. But it is quite well known that medical 
career is inherently demanding. Among the various stages that a doctor passes through, postgraduate medical training environment has always been regarded as highly stressful for the ripening doctors. Post graduate trainees are expected to be proficient clinicians, educators, and administrators at the end of the residency period. But the stress that the trainees experience during their training is amplified several folds by various factors. These include long working hours, high patient workload, poor working environment and lack of social support [6]. Such stressors are reported to have a negative psychological impact on these future doctors, including feeling less humanistic, more cynical and "burning out" during residency training.

Burnout is a psychological state that was defined by Maslach in the 1980 s as a state of physical depletion, feeling of helplessness and negative self-concept along with negative attitude towards profession and colleagues [7]. Burnout has been linked to diminished job performance (i.e., increased medical errors) and low career satisfaction [8]. These may result in malpractice suits that can have calamitous consequences, both for the patient and the doctor himself [9]. On individual level, burnout may be a contributing factor to broken relationships and mental health problems including substance use and suicidal ideations [10].

Post graduate training is the process, passing through which, the trainees acquire the skills necessary to become proficient clinicians. But this stage is inherently stressful notwithstanding the fact that trainees in Pakistan have to attend to more than 60 patients per day and work more than 80 hours per week. Such circumstances may not only pose them to burnout but may negatively impact empathy which might hinder doctor-patient communication, hence, lowering patient satisfaction and treatment compliance. Thus, a vicious cycle of elevated burnout, reduced empathy and reduced compliance can initiate which may result in treatment failure thus contributing to more patient influx. Such a situation will not only drain physician's energy and the limited resources that the hospital thrives on but will also result in escalation of emotions which results in doctor patient conflict, as is quite often seen in public sector hospitals of Pakistan. It is, therefore, necessary to determine burnout and assess its associated factors, to effectively address the needs and problems of the trainees in our setup. This will help tailor our medical education and training systems to mold our training according to job stresses and requirements.

In Pakistan, burnout has not been a topic of active research interest, as there have only been a handful of studies on the subject. Recently, a study was conducted in Lahore, determining the prevalence of burnout among gynecological residents [11]. To our knowledge, no study has yet been conducted in Pakistan, which effectively determines the factors associated with burnout among resident physicians. Furthermore, no study was found assessing empathy among residents in Pakistan. Thus, owing to the paucity of literature on burnout and empathy in Pakistan, we set out the following objectives:

1) To determine the prevalence of burnout and to identify various socio-demographic factors which are associated with resident burnout.

2) To assess levels of empathy among the residents.

\section{MATERIALS AND MethodS}

\section{A. Study Design and Study Population}

A descriptive cross-sectional study was performed among residents working in Holy Family Hospital, Benazir Bhutto Hospital and District Headquarter Hospital, all of which are situated in district Rawalpindi of Punjab, Pakistan. Data was collected from January 2019 to April 2019 using convenient sampling technique.

\section{B. Tools used for Assessment of Study Variables}

Burnout was measured using the English version of the Maslach Burnout Inventory, a widely used and validated 22item scale. MBI is considered the gold standard for identifying burnout in medical research [12]. It measures three domains: emotional exhaustion, depersonalization, and personal accomplishment. Scores for each domain and a cumulative score representing burnout was calculated. The answers are marked on a seven-grade scale of emotion occurrence frequency ranging from "never" to "daily" [2]. A high degree of burnout is reflected in high scores on the emotional exhaustion (EE) and depersonalization (DP) subscales and low scores on the personal accomplishment (PA) subscale [13]. As in a previous study, we defined high burnout considering the most common definition, high sub score on either the EE or DP subscales (EE $\geq 27$ or DP $\geq 10$ ) [13].

Empathy was assessed through the Jefferson Scale of Physician Empathy (JSPE). JSPE consists of 3 factors: Perspective Taking (PT), Compassionate Care (CC) and Standing in Patient's Shoes (SIPS). Scores for each of the above-mentioned factors and one cumulative score (by the sum of the factors) for empathy was calculated, with higher scores (ranging from 20 to 140 for the total scale) indicating higher empathy. Responses were marked on a seven-point Likert-type scale, where $1=$ "Strongly disagree" and $7=$ "Strongly agree [2].

The following socio-demographic data was also collected: age, gender, marital status, number of children, surgical/nonsurgical trainee, year of training and average weekly working hours.

\section{Data Analysis}

For data analysis IBM SPSS (C) version 25.0 has been used. Descriptive statistics were used to summarize the quantitative variables. Chi- square test was used to determine the association between burnout and categorical variables. Then, those independent variables with $\mathrm{P}$-value $<0.05$ were subjected to binary logistic regression to identify predictors of burnout. A P-value of $<0.05$ was used as the criterion for statistical significance and OR with $95 \%$ confidence interval was used to indicate the strength of association. Independent sample t-test was used to assess empathy among the groups.

\section{RESULTS}

\section{A. Description of Sample}

A total of 282 residents were included in the present study. The demographic characteristics for this sample are shown in Table I. Average age of the assessed was $27.56 \pm 1.84$. There were 156 males and 126 females. 


\section{B. Prevalence of Burnout}

The prevalence of burnout in our sample was $78 \%$. The average burnout score of the sample was $81 \pm 13.45$.

\section{Factors Associated with Resident Burnout}

Type of specialty and weekly working hours were significantly associated with residents' burnout as shown in Table II.

\section{Empathy among Residents}

Table IV shows the levels of empathy among residents. Residents differing in their weekly working hours exhibited a significant difference in empathy, with higher empathy pertaining to physicians working less than 80 hours and it is statistically significant. Average empathy score of the whole sample was $79.46 \pm 14.34$.

\begin{tabular}{|c|c|c|}
\hline & $\mathrm{N}$ & Percent \\
\hline \multicolumn{3}{|l|}{ Age } \\
\hline$<30$ & 239 & 79.7 \\
\hline$>30$ & 43 & 14.3 \\
\hline \multicolumn{3}{|l|}{ Gender } \\
\hline Male & 156 & 52 \\
\hline Female & 126 & 42 \\
\hline \multicolumn{3}{|l|}{ Marital status } \\
\hline Married & 69 & 23 \\
\hline Unmarried & 213 & 71 \\
\hline \multicolumn{3}{|l|}{ Children } \\
\hline Yes & 140 & 46.7 \\
\hline No & 142 & 47.3 \\
\hline \multicolumn{3}{|l|}{ Specialty } \\
\hline Surgical & 130 & 43.3 \\
\hline Medical & 152 & 50.7 \\
\hline \multicolumn{3}{|l|}{ Year of training } \\
\hline 1 & 119 & 39.7 \\
\hline 2 or more & 163 & 54.3 \\
\hline \multicolumn{3}{|l|}{$\begin{array}{l}\text { Average weekly } \\
\text { working hours }\end{array}$} \\
\hline$<80$ & 63 & 21 \\
\hline$>80$ & 219 & 73 \\
\hline
\end{tabular}

TABLE II: FACTORS ASSOCIATED WITH BURNOUT OF RESIDENT PHYSICIANS

\begin{tabular}{ccccc}
\hline \multicolumn{5}{c}{ PHYSICIANS } \\
Variable & Categories & $\begin{array}{c}\text { Burnout } \\
\%\end{array}$ & x2 & P-value \\
\hline \multirow{2}{*}{ Age } & $<30$ & 77 & 0.03 & 0.856 \\
& $\geq 30$ & 79 & & \\
Gender & Male & 80 & 0.91 & 0.340 \\
& Female & 75 & & \\
Marital status & Married & 82 & 0.87 & 0.351 \\
& Unmarried & 76 & & \\
Children & Yes & 77 & 0.26 & 0.608 \\
& No & 80 & & \\
Specialty & Medical & 82 & 4.579 & 0.032 \\
Year of & Surgical & 72 & & \\
Training & 1 & 73 & 2.88 & 0.089 \\
Weekly & $\geq 2$ & 81 & & \\
working hours & $\leq 80$ & 65 & 7.91 & 0.005 \\
\hline
\end{tabular}

TABLE III: LOGISTIC REGRESSION OF ASSOCIATED FACTORS AND BURNOUT AMONG RESIDENTS

\begin{tabular}{|c|c|c|}
\hline Variable Categories & COR (CI 95\%) & AOR (CI 95\%) \\
\hline \multicolumn{3}{|l|}{ WWH } \\
\hline$\leq 80$ & 1 & 1 \\
\hline$>80$ & $2.40(1.29-4.46)$ & $2.700(1.42-5.120)$ \\
\hline Specialty Medical & $1.85(1.04-3.28)$ & $2.097(1.16-3.78)$ \\
\hline Surgical & 1 & 1 \\
\hline
\end{tabular}

TABLE IV: EMPATHY AMONG RESIDENTS

\begin{tabular}{cccc}
\multicolumn{4}{c}{ TABLE IV: EMPATHY AMONG RESIDENTS } \\
\hline Variable & Categories & Mean \pm SD & P-value \\
\hline \multirow{2}{*}{ Age } & $<30$ & $79.66 \pm 14.27$ & \multirow{2}{*}{0.587} \\
& $\geq 30$ & $78.37 \pm 14.84$ & \\
Gender & Male & $78.87 \pm 14.29$ & 0.443 \\
& Female & $80.19 \pm 14.42$ & \\
Marital Status & Married & $80.45 \pm 15.55$ & 0.498 \\
& Unmarried & $79.12 \pm 13.92$ & \\
Children & Yes & $81.07 \pm 15.18$ & 0.299 \\
& No & $78.97 \pm 14.07$ & \\
YOT & 1 & $78.64 \pm 15.11$ & 0.412 \\
& $\geq 1$ & $80.06 \pm 13.7$ & \\
Specialty & Medical & $78.31 \pm 14.07$ & 0.145 \\
& Surgical & $80.81 \pm 14.58$ & \\
WWH & $<80$ & $83.66 \pm 15.98$ & 0.008 \\
& $\geq 80$ & $78.26 \pm 13.63$ & \\
\hline
\end{tabular}

\section{DISCUSSION}

To our knowledge, it is the first study examining burnout and empathy among residents in Pakistan.

In our study, approximately $78 \%$ of the residents were found to experience burnout, which is relatively less as compared to their Saudi colleagues [13]. But burnout among residents in our sample was higher than American residents [15]. In our study the factors most likely to predict burnout are average weekly working hours and specialty of the residents. Residents with a greater weekly workload i.e., increased weekly working hours experienced high burnout. This result is consistent with the studies conducted earlier [13], [16]. In our sample, residents worked about 83 hours per week and 56 percent of the residents worked more than 80 hours per week which is a far greater than the residents working in Saudi Arabia and United States [13], [16]. Weekly working hours of residents were restricted to under 80 hours per week by the Accreditation Council for Graduate Medical Education (ACGME) [14]. In the light of our findings, it is, therefore, suggested to reduce weekly working hours of the resident physicians working in our setting to promote quality of care being delivered to our patients. Moreover, in addition to cultivating skills such as resilience and stress coping strategies, efforts must be directed towards reducing administrative responsibilities that add to the residents' workload, in favor of the doctor-patient relationship [2]. Internal medicine residents were more prone to develop burnout as compared to surgical residents. No differences between burnout and empathy were observed according to age, gender, and marital status. It confirms to the studies conducted earlier [1], [5]. Comparing the above results to the French research, it should be noted that the mean empathy scores were greater for French physicians whereas the Pakistani physicians had greater mean burnout score than their French colleagues [2]. If we take MBI and JSPE subscales into account, Pakistani physicians had greater mean EE and DP scores on MBI, but a low PT, CC and SIPS mean score on JSPE than French physicians [2]. In the light of a study conducted in Singapore, Pakistani physicians had a lower mean score of empathy [17]. 


\section{LIMITATIONS}

The main limitation of our study is its descriptive crosssectional design, which is unable to establish a causal relationship between burnout and empathy. Secondly, the sample was not randomized so there might be a possibility of participation bias.

\section{SCOPE FOR FUTURE RESEARCH}

Observational studies should be conducted to investigate the causal relationship between burnout and empathy. Further research should be conducted to identify the factors responsible for causing burnout in our setting.

\section{CONCLUSION}

This study identifies weekly working hours as the main contributor to development of burnout among residents. Therefore, it might be fruitful to measure burnout in residents to identify doctors who are at a risk of developing burnout. They could then be offered interventions aimed at reducing burnout and improving empathic engagements, thus enhancing patient doctor-patient relationship, patient compliance and satisfaction and ultimately obtaining favorable clinical outcomes.

\section{ACKNOWLEDGEMENTS}

We would like to thank all the doctors who dedicated their time to participate in this study.

\section{CONFLICT OF INTEREST}

The authors confirm that there is no conflict of interest.

\section{REFERENCES}

[1] Yuguero O, Marsal R, Esquerda M, et al. European Journal of General Practice Association between low empathy and high burnout among primary care physicians and nurses in Lleida, Spain Association between low empathy and high burnout among primary care physicians and nurses in Lleida, Spain. Eur J Gen Pract. 2016;23(1):4-10. doi:10.1080/13814788.2016.1233173.

[2] Sturzu L, Lala A, Bisch M, Guitter M, Dobre D, Schwan R. Empathy and Burnout-A Cross-Sectional Study Among Mental Healthcare Providers in France. J Med Life. 12:21-29. doi:10.25122/jml-20180050.

[3] Hojat M, Gonnella JS, Mangione S, Nasca TJ, Magee M. Physician empathy in medical education and practice: experience with the jefferson scale of physician empathy. 2003. doi:10.1016/S15431150(03)00002-4.

[4] Ridd M, Shaw A, Lewis G, Salisbury C. The patient-doctor relationship: A synthesis of the qualitative literature on patients' perspectives. $\mathrm{Br} \quad \mathrm{J}$ Gen Pract. 2009; 59(561): 268-275. doi:10.3399/bjgp09X420248

[5] Torres OY, Areste ME, Mora JRM, Soler-Gonzalez J. Association between sick leave prescribing practices and physician burnout and $\begin{array}{llll}\text { empathy. } & \text { PLoS } & \text { One. }\end{array}$ doi:10.1371/journal.pone.0133379.

[6] Ogundipe OA, Olagunju AT, Lasebikan VO, Coker AO. Burnout among doctors in residency training in a tertiary hospital. Asian $J$ Psychiatr. 2014;10(August):27-32. doi:10.1016/j.ajp.2014.02.010.

[7] Wilkinson H, Whittington R, Perry L, Eames C. Examining the relationship between burnout and empathy in healthcare professionals: A systematic review. 2017. doi:10.1016/j.burn.2017.06.003.
[8] Arfken C. Burnout comparison among residents in different medical specialties injection opioid use among black patients at an urban methadone clinic: an evaluation of risk/protective factors to injection status view project sleep research at ROMHC view project. 2004. doi:10.1176/appi.ap.28.3.240.

[9] Lee YY, Medford ARL, Halim AS. Burnout in physicians. J R Coll Physicians Edinb. 2015;45(2):104-107. doi:10.4997/JRCPE.2015.203

[10] Lee PT, Loh J, Sng G. Empathy and burnout: a study on residents from a Singapore institution.

[11] Waheed K, Liaqat N, Ejaz S, et al. Burnout among gynaecological residents in lahore, Pakistan: A cross-sectional survey. J Pak Med Assoc. 2017;67(9):1318-1322.

[12] Romani M, Ashkar K. Burnout among physicians. Libyan J Med. 2014;9(1). doi:10.3402/ljm.v9.23556.

[13] Hameed TK, Masuadi E, Al Asmary NA, Al-Anzi G, Saleh M, Dubayee A. A study of resident duty hours and burnout in a sample of Saudi residents. doi:10.1186/s12909-018-1300-5.

[14] Kawamura Y, Takayashiki A, Ito M, Maeno T, Seo E, Maeno T. Stress Factors Associated with Burnout Among Attending Physicians: A Cross-Sectional Study. Orig Artic J Clin Med Res. 2018;10(3):226232. doi:10.14740/jocmr3299w.

[15] Ripp J, Babyatsky M, Fallar R, et al. The incidence and predictors of job burnout in first-year internal medicine residents: A five-institution study. Acad Med. 2011;86(10):1304-1310. doi:10.1097/ACM.0b013e31822c1236.

[16] Golub JS, Weiss PS, Ramesh AK, Ossoff RH, Iii MMJ. Burnout in Residents of Otolaryngology - Head and Neck Surgery: A National Inquiry into the Health of Residency Training. 2007;82(6):596-601.

[17] Lee PT, Sng G, Loh J, Tung J, Yeo KK. Authors' reply: Comment on Empathy and burnout: A study on residents from a Singapore institution. Singapore Med J. 2018;59(3):168. doi:10.11622/smedj.2018034.

[18] Wilczek-Rużyczka E. Empathy vs. professional burnout in health care professionals. J US-China Med Sci. 2011;8(9):526-532.

[19] Yuguero O, Melnick ER, Marsal JR, Esquerda M, Soler-Gonzalez J. Cross-sectional study of the association between healthcare professionals' empathy and burnout and the number of annual primary care visits per patient under their care in Spain. BMJ Open. 2018;8(7):1-6. doi:10.1136/bmjopen-2017-020949.

[20] Zawieja P. Le burn out. Paris cedex 14: Presses Universitaires de France; 2015. https://www.cairn.info/le-burn-out9782130633563.htm.

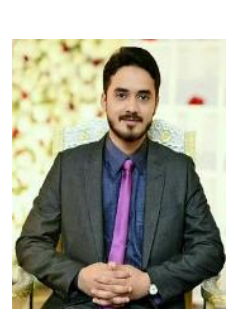

\section{Dr. Muhammad Hamza Khalid}

Place of birth: Rawalpindi, Pakistan.

Date of birth: $23^{\text {rd }}$ November 1997

Educational background: MBBS

Affiliation: Rawalpindi Medical University,

Rawalpindi, Pakistan.

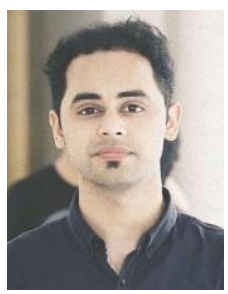

Dr. Tayyab Mumtaz Khan

Place of Birth: Lahore, Pakistan.

Date of Birth: $23^{\text {rd }}$ March 1996.

Educational Background: BSC, MBBS.

Affiliation: Rawalpindi Medical University Rawalpindi, Pakistan. 